\title{
O ETHOS DISCURSIVO NA TRADUÇÃO LITERÁRIA A PARTIR DA ANÁLISE DE DUAS TRADUÇÕES AO INGLÊS DO CONTO A CARTOMANTE DE MACHADO DE ASSIS ${ }^{1}$
}

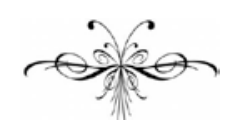

\author{
VANESSA SILVA FISCHER
}

Heloísa Orsi Koch Delgado

\begin{abstract}
Resumo: Neste artigo analisamos um texto literário em português - o conto A Cartomante, de Machado de Assis - e duas traduções suas em inglês, - a de Isaac Goldberg (1921) e a de Rosália Garcia (2011) - fazendo uso de conceitos dos Estudos da Tradução e da Análise do Discurso. Nosso objetivo principal é tratar do ethos discursivo dos tradutores e compreender como um enunciador que constroi um texto com base em outro se apropria do texto original. Busca-se sustentar a hipótese de que esse enunciador apresentará em sua linguagem, ou seja, no modo como se expressa, algum indício de opinião acerca do contexto do discurso original no qual se baseia para construir sua releitura.
\end{abstract}

Palavras-chave: Ethos discursivo; Tradução; Escolhas lexicais; A Cartomante; Machado de Assis.

\begin{abstract}
In this article we analyze a literary text in Portuguese, the tale The Fortune Teller, by Machado de Assis, and two translations of it into English, one by Isaac Goldberg (1921) and the other by Rosalia Garcia (2011). With that purpose we make use of concepts from Translation Studies and from Discourse Analysis. Our main goal is to discuss the discursive ethos of the two translators in order to understand how an enunciator who creates a text based on another appropriates the original one. Our aim is to support the hypothesis that this enunciator does reveal in its language - in other words, in the way s/he expresses himself/herself - some hint of an opinion about the context of the original speech on which he relies to develop his rereading.
\end{abstract}

Keywords: Discursive ethos; Translation; Lexical choices; A Cartomante; Machado de Assis.

\footnotetext{
${ }^{1}$ Este texto faz parte do meu Trabalho de Conclusão de Curso sob a orientação de Heloísa O. Koch Delgado, Doutora em Estudos da Linguagem pela UFRGS e Professora Adjunta da Faculdade de Letras da PUCRS.
} 
$\mathrm{N}$ este artigo, pretende-se investigar como ocorre a apropriação de textos originais em textos traduzidos e identificar possíveis características do ethos discursivo dos enunciadores-tradutores ${ }^{2}$ nesses últimos. Com esse fim, faremos uma análise comparativa entre o conto $A$ Cartomante, de Machado de Assis (2004 [1894]) ${ }^{3}$, e duas versões suas traduzidas em inglês, uma delas de Isaac Goldberg (2007 [1921]) e a outra de Rosália Garcia $(2011)^{4}$.

Cremos, aqui, na relevância de buscarmos elementos que comprovem quais são essas características que - de acordo com a Análise do Discurso - existem no processo de apropriação por parte do enunciador de um dado discurso, e que, cremos, se aplicam também ao processo de apropriação dos textos traduzidos. Promoveremos, portanto, um estudo de como o tradutor entende o texto do enunciador original para construir sua releitura. Ressaltamos o fato de que o estudo aqui apresentado apoia-se na hipótese de que no processo tradutório as escolhas lexicais e frasais podem diferir em diversos níveis com relação à versão original, visto que se trata, nesse momento, de um enunciador que constroi uma releitura de um discurso anterior.

Antes de darmos início à análise propriamente dita, eis as perguntas que norteiam este estudo:

Em que circunstâncias as escolhas lexicais de um tradutor demonstram características de seu ethos discursivo?

É possível construir uma tradução de forma imparcial com relação ao conteúdo do original?

Faz-se necessário destacar que aqui entendemos como forma imparcial quaisquer escolhas de recursos linguísticos (por exemplo, a escolha por uma determinada palavra para caracterizar algo ou alguém) de que um tradutor possa fazer uso e que seja guiada pelo ímpeto desse tradutor de ser o mais ideológica e culturalmente neutro possível em relação ao dito no original, seja pelo emprego de palavras bem entendidas como equivalentes a palavras presentes nesse último, seja por quaisquer outras escolhas lexicais que busquem aproximar o novo texto ao máximo ao texto que o tradutor tem como base. Pensando nisso, iniciaremos essa discussão trazendo, a seguir, uma breve explanação sobre um conceito-chave da Análise do Discurso: o ethos discursivo.

Ao recorrermos à teoria de Maingueneau (2002) verificamos que afirma que um texto é sempre sustentado por uma voz, e que, através do modo como se expressa, um enunciador revela indícios de sua opinião sobre aquilo que diz. Isso é o que Maingueneau chama de ethos discursivo. Ele aplica esse conceito a todo e qualquer discurso, afirmando que todo discurso é particular de cada enunciador.

\footnotetext{
${ }^{2}$ Optamos por utilizar essa expressão pelo fato de estarmos tratando de textos que, apesar de serem versões traduzidas e, portanto, terem, como base, um outro texto - que preexiste ao seu -, são, também, discursos, os quais possuem, cada um, o seu respectivo enunciador, que, à sua maneira, se apropria do texto original para criar sua retextualização.

${ }^{3}$ A Cartomante foi publicado originalmente na Gazeta de Notícias do Rio de Janeiro, em 1884, e posteriormente incluído no livro Várias Histórias, de 1896.

${ }^{4}$ Atentamos ao fato de que, com o intuito de cumprir com o que este artigo se propõe, aspectos do enredo do conto posto à análise aparecerão ao longo do texto. Apesar de crermos ser possível a compreensão da análise apresentada sem a leitura do conto em sua totalidade, informamos que o conto A Cartomante pode ser encontrado na obra supracitada - nota de rodapé de número 3 -, que está nas referências bibliográficas desse artigo.
} 
Logo, ao levarmos tal princípio teórico em consideração, tendo textos traduzidos como objeto de análise, podemos inferir que, em tese, um tradutor também sofre, de diversas formas, influências de suas próprias impressões a respeito do texto original ao construir sua releitura desse.

Seguindo esse raciocínio, o enunciador de uma tradução teria a opção de se posicionar criticamente em relação ao texto original, quer dizer, elegendo dizer à sua maneira, com as suas próprias palavras, o que é dito no texto que utiliza como base, sem seguir à risca e de forma algo literal o dito no original. Ao mesmo tempo, pode buscar e ter êxito em fazer uso de uma linguagem que demonstre seu distanciamento e imparcialidade em relação ao original, isto é, ao fazer escolhas lexicais que se aproximem semanticamente daquelas feitas pelo autor do discurso original. De antemão, vale ressaltar que ao referirmo-nos ao distanciamento e imparcialidade de um tradutor, não visamos partir do princípio de que uma tradução em que a mensagem do original foi textualizada de forma algo literal, como dizemos, não apresentará indícios de que o ethos discursivo do tradutor não se faz presente; por princípio, ele estará sempre lá.

Com o intuito de testar as hipóteses aqui levantadas, selecionamos oito segmentos do texto original, os quais foram contrapostos a seus trechos correspondentes nas duas versões traduzidas postas à análise. Lembramos, pois, que esta pesquisa é sustentada pelas seguintes hipóteses:

um enunciador-tradutor apresentará em sua linguagem, ou seja, no modo como se expressa, algum indício de opinião acerca do contexto do discurso original no qual se baseia para construir sua releitura dele;

no processo tradutório, as escolhas lexicais e frasais podem diferir em diversos níveis com relação à versão original, visto que se trata, nesse momento, de um enunciador que constroi uma releitura de um discurso anterior.

Eis aqui o primeiro trecho analisado (Figura 1), o qual foi retirado do primeiro parágrafo do texto original. Nele, Machado de Assis faz uso da seguinte expressão: “(...) há mais coisas no céu e na terra do que sonha a nossa filosofia”.

\begin{tabular}{|l|l|l|l|}
\hline Segmento & \multicolumn{1}{|c|}{ Original } & \multicolumn{1}{|c|}{ Garcia } & \multicolumn{1}{c|}{ Goldberg } \\
\hline $\mathbf{1}$ & $\begin{array}{l}\text { Hamlet observa a } \\
\text { Horácio que há mais } \\
\text { coisas no céu e na } \\
\text { terra do que sonha a } \\
\text { nossa filosofia. }\end{array}$ & $\begin{array}{l}\text { Hamlet remarks to } \\
\text { Horatio that there are } \\
\text { more things in heaven } \\
\text { and earth than are } \\
\text { dreamt of in his } \\
\text { philosophy. }\end{array}$ & $\begin{array}{l}\text { Hamlet observes to } \\
\text { Horatio that there are } \\
\text { more things in heaven } \\
\text { andeamt of in our } \\
\text { philosophy. }\end{array}$ \\
\hline
\end{tabular}

Temos aqui um exemplo de uma colocação, "no céu e na terra" que em ambas as traduções foi retextualizada com termos que, mesmo em outra língua, revelam equivalência e, mais que isso, corespondência retórica com os termos utilizados na versão original, conseguindo apresentar, de forma literal, a mensagem nela contida. Esse é um exemplo cujo significado provavelmente se perderia se ele fosse retextualizado com termos que não apresentassem equivalência e correspondência com o original. 
Nesse momento, faz-se necessária uma explanação a respeito de dois importantes conceitos dos Estudos da Tradução utilizados neste estudo e citados acima: retextualização e equivalência.

Costa (2005) faz a seguinte análise a respeito do conceito de equivalência em uma tradução:

(...) o texto do tradutor deve ter um alto grau de semelhança com o seu correspondente original para que seja reconhecido como uma tradução. Nos estudos de tradução, essa semelhança é atualmente denominada equivalência. (p. 26)

Esse autor aponta que para atingir a equivalência no processo tradutório é preciso lembrar nesse processo que há dois aspectos: um deles é o da equivalência dos itens no nível da oração, ou como indica o autor (p. 27), a equivalência propriamente dita, e a outra é a equivalência em nível supra-oracional, ou a equivalência (macro)textual. Costa ainda explica que há outro aspecto crucial no processo tradutório: a construção de um novo texto. A esse processo, seguindo Coulthard $(1987)^{5}$, Costa dá o nome de textualização.

Fazemos a este ponto um esclarecimento a respeito da concepção de equivalência na qual este estudo se sustenta. Entende-se aqui, seguindo Costa, que a equivalência existe em uma dada tradução quando existe um alto grau de semelhança entre o dito no original e o dito na tradução. Entretanto, essa equivalência, como afirma Costa, não se refere somente ao nível lexical; tal equivalência, subscrevemos, diz respeito também, e talvez principalmente, opinamos, à relação de semelhança entre a mensagem do original e a mensagem transmitida na tradução. A partir daí, acreditamos que a literalidade nem sempre é necessária para que tal equivalência seja estabelecida entre original e tradução; por vezes, como veremos em diversos dos exemplos destacados neste estudo, existem formas diversas de se retextualizar uma mensagem e mesmo assim se obter como resultado traduções cujas mensagens sejam plenamente relacionáveis ao original.

Voltando ao objeto de nossa análise na Figura 1, pode-se dizer que a expressão em tela - no céu e na terra - é também um exemplo de sequência léxicogramatical fixa, pois o sentido global da expressão se dá através de um arranjo específico dos termos na frase. Isso significa que, assim como outros exemplos de sequências léxico-gramaticais fixas, a expressão presente no trecho que introduz o conto só pode ser reproduzida com esse arranjo dos seus termos-chave - céu e terra para que o efeito desejado seja alcançado. Sendo assim, entende-se que neste caso seria inadequado reproduzir a mesma sentença da seguinte forma: "existem mais coisas na terra e no céu (...)”. Por coincidência, em inglês existe expressão idiomática que apresenta a mesma sequência - move heaven and earth -, o que facilita o uso da sequência lexical em inglês de modo semelhante a em português.

Atentamos a este ponto que não faz parte do objetivo desse trabalho o ato de julgar nenhuma das versões traduzidas de modo a apontar a melhor retextualização. Ao contrário, entendemos que toda e qualquer tradução em que o discurso se faz entender, transmitindo sua mensagem de forma adequada - e que, claro, tenha relação ao dito no texto original -, pode ser considerada uma boa retextualização.

\footnotetext{
${ }^{5}$ A referência desta obra pode ser encontrada em Costa (2005).
} 
Ainda com respeito aos segmentos da Figura 1, percebemos que o verbo observar foi traduzido com termos equivalentes, mas de valores não exatamente idênticos em inglês. Mais precisamente, vemos a diferença entre o caráter um tanto mais formal do verbo observe em relação ao verbo remark, como pode ser visto no dicionário bilíngue de língua inglesa e portuguesa Longman Dicionário Escolar (2008). O verbo 'observe', utilizado por Goldberg é caracterizado como mais formal do que o verbo remark, empregado por Garcia.

Desse modo, podemos levantar duas hipóteses: i. a de que Goldberg optou por utilizar essa formalidade com o intuito de fazer dela uma marca da sua retextualização, enquanto Garcia elegeu um verbo de valor mais informal; ii. é também imaginável que Garcia possa ter escolhido este verbo para diferenciar sua tradução daquela de Goldberg, que antecede à sua.

O trecho da Figura 2 (a seguir) nos conduz à identificação de elementos que julgamos abrangidos por aspectos de dois dos conceitos em que esta análise se apoia: o de ethos discursivo, de Mainguenau (2002), e o de clarificação, de Berman (2007).

\begin{tabular}{|c|c|c|c|}
\hline Segmento & Original & Garcia & Goldberg \\
\hline 4 & $\begin{array}{l}\text { Apenas começou a } \\
\text { botar as cartas, disse- } \\
\text { me: “A senhora gosta } \\
\text { de uma pessoa...” } \\
\text { Confessei que sim, e } \\
\text { então ela continuou a } \\
\text { botar as cartas, } \\
\text { combinou-as, e no fim } \\
\text { declarou-me que eu } \\
\text { tinha medo de que } \\
\text { você me esquecesse, } \\
\text { mas que não era } \\
\text { verdade... }\end{array}$ & $\begin{array}{l}\text { She had just started } \\
\text { laying her cards on } \\
\text { the table when she } \\
\text { said: 'You are in love } \\
\text { with someone...' } \\
\text { I confessed I was, } \\
\text { and she went on } \\
\text { laying her cards, } \\
\text { combining them and, } \\
\text { in the end, stated that } \\
\text { I was afraid that you } \\
\text { had forgotten me, but } \\
\text { that it was not true..." }\end{array}$ & $\begin{array}{l}\text { Scarcely had she } \\
\text { begun to lay out the } \\
\text { cards when she said to } \\
\text { me: 'The lady likes a } \\
\text { certain person ...' I } \\
\text { confessed that it was } \\
\text { so, and then she } \\
\text { continued to rearrange } \\
\text { the cards in various } \\
\text { combinations, finally } \\
\text { telling me that I was } \\
\text { afraid you would } \\
\text { forget me, but that } \\
\text { there were no grounds } \\
\text { for my fear." }\end{array}$ \\
\hline \multicolumn{4}{|c|}{ Figura 2} \\
\hline
\end{tabular}

A nosso ver, os dois conceitos se atrelam nessa análise na medida em que, por um lado, verificamos que, em determinadas passagens de seus discursos, cada tradutor faz uso de diferentes recursos para atingir o objetivo de transmitir a mensagem do original, denotando a manifestação de seus ethos discursivos. Por vezes a retextualização do contexto do original se dá de forma a apontar para aspectos que não estão nele explícitos, o que entendemos ser a manifestação da referida clarificação, que, segundo Berman (p. 50, 2007), é uma de suas tendências deformadoras, um conjunto de manifestações de cunho estético-linguístico que, segundo o autor, "deformam" o texto traduzido).

No caso presente, vemos que os tradutores tiveram interpretações distintas para a frase "A senhora gosta de uma pessoa". Enquanto Goldberg retextualiza o verbo gostar com um verbo semanticamente equivalente na língua inglesa - like -, Garcia opta pelo verbo love (amar, em português). 
Percebemos que ambas as traduções foram construídas de modo que a mensagem do original fosse mantida. Entretanto, vemos que as escolhas por verbos de intensidades diferentes - like e love - ressaltam prováveis opiniões pessoais de cada tradutor, isto é, tais escolhas podem ser interpretadas como informando algo a respeito de seus ethos discursivos.

Reiteramos aqui nossa crença de que embora possam ocorrer eventuais interferências - de opinião do enunciador-tradutor - no processo de tradução, elas, em princípio, não se tornam empecilho para a construção de uma tradução que possa ser considerada adequada.

Compartilhamos da ideia de que a literalidade pode ser um recurso útil, dependendo da mensagem a ser traduzida; ao mesmo tempo, partimos do princípio de que isso não quer dizer que não haverá casos em que, em vez da literalidade, a escolha por uma abordagem diversa possa ser uma melhor alternativa para transmitir a mesma mensagem com outras palavras.

Podemos verificar na Figura 2 na tradução de 'mas que não era verdade' a literalidade se faz presente somente na retextualização de Garcia, que fez uso de termos de estrita equivalência semântica (but that it was not true) com relação aos termos da frase original. Goldberg, no entanto, utiliza outros recursos para comunicar a mesma mensagem, retextualizando o original com a frase 'but that there were no grounds for me to fear'. Nota-se que o ethos discursivo de Goldberg se inclina mais para o seu próprio ideacional, isto é, busca incluir os conceitos que ele próprio construiu com base em sua interpretação do original. Seu ethos discursivo demonstra ainda que seu discurso possui uma carga psicológica e de ideologia particulares na interpretação do trecho. Nossa crença é que isso se explica pelo fato de que na retextualização feita por esse tradutor ele imprime certo indício de opinião a respeito do enredo ao apontar que acredita haver "amor" entre os personagens Camilo e Rita, independente das inseguranças dessa última.

Podemos dizer, ainda, que esse tradutor usa como recurso a clarificação, "tendência deformadora" que revela aquilo que se mostra indefinido no original (Berman, p. 50-51, 2007), trazendo a imposição do definido; em outras palavras, aquilo que está oculto se faz aparente, e acabam surgindo, assim, para o texto, aqueles elementos que não ditos no original, mas que fazem parte do seu contexto, mesmo que implicitamente. Nesse caso, o que se mostra indefinida e implícita é a afirmação que há por trás da sentença 'there were no grounds for me to fear'. Traduzindo essa frase para o português, vemos que ela equivale a "não há motivos para temer”. A mensagem que, em nossa opinião, o tradutor pretende passar com essa tradução do original é a de que Rita, não tem motivos para temer "ser esquecida" por Camilo.

É possível supor que, implicitamente, Goldberg quis trazer para seu texto a sua crença de que o personagem Camilo não esqueceria Rita - e por isso, ela não deveria temer.

Não podemos deixar de lado nesta análise o fator de opinião do enunciadortradutor, sobre o qual vimos discutindo. Compartilhamos da ideia de que o fator ideológico, que pode aparecer em dado momento na versão traduzida de um discurso, está intrinsecamente atrelado às experiências e conhecimentos prévios do enunciador que o produz. Sendo assim, em princípio, esses fatores influenciariam esse enunciador na construção de seu texto.

É valido reiterar que apostamos na influência de diversos fatores na construção do ideacional de um texto traduzido. Mais que isso, pensamos que, por vezes, essas influências ficarão evidentes na linguagem que o tradutor utiliza. 
Sobre essa questão, Tymoczko (2003), por exemplo, menciona aquilo que chama de postura do tradutor $^{6}$ e afirma que a ideologia de uma tradução não está simplesmente no texto traduzido em si, mas na postura do tradutor. Porém, também não podemos esquecer que, por vezes, o intuito de um tradutor é, de fato, fazer uso de recursos que o possibilitem construir os blocos ideacionais do texto traduzido de forma a não demonstrar alguma pista de sua opinião sobre o texto original. Crê-se aqui, pois, que sua escolha por um recurso ou outro dependerá de diversos fatores. Dentre eles destacamos as intenções que esse tradutor pode, por ventura, ter para o seu discurso.

Voltando à nossa análise, vimos que no caso da tradução feita por Goldberg, algumas de suas escolhas lexicais não trouxeram literalidade, mas apresentaram um ajuste necessário aos olhos deste tradutor. Goldberg fez surgir um elemento que fazia parte do contexto - there were no grounds for me to fear $^{7}$ - mas que não era dito com as mesmas palavras na versão original. Já a tradução de Garcia é marcada por uma maior literalidade. Ela também alcançou o objetivo de se fazer entender, mas deu prioridade a uma transcrição mais próxima da mensagem do texto original - that it was not true. Reiteramos aqui que cada retextualização foi construída a sua forma, mas que ambas apresentam mensagens entendíveis e coerentes em relação com o contexto original do conto.

Vemos que, por vezes, a literalidade se faz presente em ambas as traduções analisadas e de um modo similar. Em contrapartida, ambas também apresentam trechos em que, em vez da literalidade, tem-se a exposição de um ponto de vista de algum aspecto oculto ou simplesmente não mencionado no texto original, mas que, aos olhos do tradutor, pareceu relevante ser trazido à tona.

Constatamos também que ambos os tradutores fizeram escolhas léxicogramaticais que, em nossa opinião, fornecem indícios dos ethos discursivos de cada um deles.

Para introduzir essa discussão, concentremo-nos, primeiramente, na análise de um certo parágrafo (Figura 3) em que há uma conversa entre Rita e Camilo. Os dois falam sobre a possibilidade de Rita ter sido vista por Vilela - seu marido, que ela traíra com Camilo - enquanto ia até a casa da cartomante.

\footnotetext{
${ }^{6}$ Stance of the translator (tradução da autora desse artigo).

${ }^{7}$ A fim de elucidar o leitor deste artigo a respeito de aspectos referente ao contexto da história de $A$ cartomante, vale lembrar que, na trama, Rita vai à cartomante pois teme que Camilo a esqueça.
} 


\begin{tabular}{|c|c|c|c|}
\hline Segmento & Original & Garcia & Goldberg \\
\hline 8 & $\begin{array}{l}\text { (...) Depois, } \\
\text { repreendeu-a; disse- } \\
\text { lhe que era } \\
\text { imprudente andar por } \\
\text { essas casas. Vilela } \\
\text { podia sabê-lo, e } \\
\text { depois... } \\
\text { - Qual saber! Tive } \\
\text { muita cautela, ao } \\
\text { entrar na casa. } \\
\text { - Onde é a casa? } \\
\text { - Aqui perto, na Rua } \\
\text { da Guarda Velha; não } \\
\text { passava ninguém } \\
\text { nessa ocasião. } \\
\text { Descansa; eu não sou } \\
\text { maluca. }\end{array}$ & $\begin{array}{l}\text { Afterwards, } \\
\text { reproached her, } \\
\text { warned her it was } \\
\text { rash to go to these } \\
\text { houses. Vilela might } \\
\text { find out and then... } \\
\text { "He'll never know! I } \\
\text { was very cautious } \\
\text { when I entered the } \\
\text { house." "Where is it?" } \\
\text { "Not far from here, } \\
\text { on Guarda Velha } \\
\text { Street. Nobody was } \\
\text { on the street while I } \\
\text { was there. Relax, I'm } \\
\text { not reckless." }\end{array}$ & $\begin{array}{l}\text { Then he reproved her, } \\
\text { saying that it was } \\
\text { imprudent to visit } \\
\text { such houses. Villela } \\
\text { might learn of it, and } \\
\text { then ... } \\
\text { "Impossible! I was } \\
\text { exceedingly careful } \\
\text { when I entered the } \\
\text { place." } \\
\text { "Where is the house?" } \\
\text { "Near here. On } \\
\text { Guarda-Velha Street. } \\
\text { Nobody was passing } \\
\text { by at the time. Rest } \\
\text { easy. I'm not a fool." }\end{array}$ \\
\hline \multicolumn{4}{|c|}{ Figura 3} \\
\hline
\end{tabular}

Logo no início da fala da personagem Rita, temos uma expressão - Qual saber! - que dificilmente poderia ser traduzida de forma literal. Ainda sim, ambos os tradutores mantiveram a coerência e a relação com o que estava sendo dito naquele trecho. Enquanto Garcia traduziu esta primeira fala como 'He'll never know!', Goldberg preferiu utilizar menos palavras e fazer uso de recurso retórico para passar a mensagem, retextualizando esse fragmento com 'Impossible!'.

Porém, vale fazer referência a outro detalhe que difere entre as traduções de Garcia e Goldberg. Enquanto Goldberg escolhe fazer referência ao personagem Vilela através da frase 'He'll never', com o intuito de retomar que Rita traíra alguém, o marido Vilela, referido pelo pronome 'he', Garcia dá ênfase à situação em si, e não refere o marido.

É notório que as escolhas lexicais de ambos os tradutores demonstraram certo posicionamento diante do enredo do conto, pois cada um priorizou um aspecto distinto do contexto em sua abordagem. Isso pode ser constatado por meio da observação das traduções da passagem 'não sou maluca', em que Goldberg e Garcia optaram em suas retextualizações pelas frases 'I'm not a fool' e 'I'm not reckless', respectivamente. Novamente, nesse caso vemos que os adjetivos utilizados diferem semanticamente, visto que, de acordo com o Michaelis Moderno Dicionário Inglês \& Português (on-line), 'fool' significa 'bobo' ou 'tolo', enquanto 'reckless' possui, dentre outros equivalentes na língua portuguesa, o de 'descuidado', o qual, levando em conta o contexto do trecho e do conto como um todo, tem certa relação com o contexto do trecho original em questão - (...) não sou maluca -. Essa diferença demarca a provável distinção entre as impressões da mensagem tidas por cada tradutor: 'fool', nesse caso, poderia imprimir um aspecto de malícia que Goldberg possa ter procurado atribuir à personagem Rita.

Salientamos que, ainda que tenhamos tido essa interpretação, é também possível encarar essas escolhas lexicais como a recorrente necessidade de, em uma 
tradução, se formular um discurso escrito que apresente certa literalidade em relação aos dizeres do texto original.

Veremos também que, como nos exemplos ilustrados na Figura 3, outros trechos do original foram traduzidos com elementos que sugerissem pistas do posicionamento dos tradutores acerca do contexto desse texto. afirmação.

O próximo trecho a ser analisado (Figura 4) pode servir de exemplo para essa

\begin{tabular}{|c|c|c|c|}
\hline Segmento & Original & Garcia & Goldberg \\
\hline 14 & $\begin{array}{l}\text { Separaram-se } \\
\text { contentes, ele ainda } \\
\text { mais que ela. Rita } \\
\text { estava certa de ser } \\
\text { amada; Camilo, não } \\
\text { só o estava, mas via-a } \\
\text { estremecer e arriscar- } \\
\text { se por ele, correr às } \\
\text { cartomantes. (...) }\end{array}$ & $\begin{array}{l}\text { They parted in high } \\
\text { spirits, he even more } \\
\text { than she Rita was } \\
\text { certain she was loved; } \\
\text { Camilo was not only } \\
\text { certain, but saw her } \\
\text { shudder and take risks } \\
\text { for him, running off } \\
\text { to fortunetellers. }\end{array}$ & $\begin{array}{l}\text { The lovers parted in } \\
\text { good spirits, he more } \\
\text { happy than she. Rita } \\
\text { was sure that she was } \\
\text { loved; but Camillo } \\
\text { was not only sure that } \\
\text { she loved him, but } \\
\text { saw how she trembled } \\
\text { for him and even took } \\
\text { risks, running to } \\
\text { fortune-tellers. }\end{array}$ \\
\hline 15 & $\begin{array}{lr}\text { A casa do encontro } \\
\text { era na antiga Rua dos } \\
\text { Barbonos, onde } \\
\text { morava ra } \\
\text { comprovinciana de } \\
\text { Rita. Esta desceu pela } \\
\text { Rua das Mangueiras, } \\
\text { na direção r de } \\
\text { Botafogo, onde } \\
\text { residia; Camilo } \\
\text { desceu pela da } \\
\text { Guarda Velha, } \\
\text { olhando de passagem } \\
\text { para a casa da } \\
\text { cartomante. }\end{array}$ & $\begin{array}{l}\text { Their meeting spot } \\
\text { was on old Barbonos } \\
\text { Street where lived a } \\
\text { friend of Rita's from } \\
\text { her hometown. Rita } \\
\text { walked down } \\
\text { Mangueiras Street } \\
\text { towards Botafogo } \\
\text { where she lived. } \\
\text { Camilo strolled down } \\
\text { Guarda Velha Street, } \\
\text { glancing fleetingly at } \\
\text { the fortuneteller's } \\
\text { house. }\end{array}$ & $\begin{array}{l}\text { Their secret meeting- } \\
\text { place was in the old } \\
\text { Barbonos street at the } \\
\text { home of a woman } \\
\text { that came from Rita's } \\
\text { province. Rita went } \\
\text { off through } \\
\text { Mangueiras street, in } \\
\text { the direction of } \\
\text { Botafogo, where she } \\
\text { resided; Camillo } \\
\text { entered Guarda-Velha } \\
\text { street, keeping his eye } \\
\text { open, as he passed, } \\
\text { for the home of the } \\
\text { card reader. }\end{array}$ \\
\hline \multicolumn{4}{|c|}{ Figura 4} \\
\hline
\end{tabular}

Logo no início do segmento 14, vemos que Machado não menciona os personagens pelo nome. Pelo fato de ser possível inferir que o verbo 'separar' referese aos personagens Rita e Camilo, e também pelo fato de eles terem sido mencionados no parágrafo que antecede a esse trecho, o autor da obra inicia esse parágrafo com o modo desinencial dos sujeitos da frase 'separaram-se'.

No entanto, por imposição da língua inglesa, que requer o emprego de um nome, ou de um pronome, para referir alguém ou alguma coisa, os tradutores fizeram diferentes escolhas referenciais, e gramaticais ao retextualizarem o início do parágrafo. Goldberg utilizou a palavra 'lovers', que, de acordo com o Michaelis 
Moderno Dicionário Inglês \& Português (on-line), apresenta, dentre outras definições, as seguintes: i. amante, amado; ii. namorado; iii. pessoa que tem grande predileção ou amor por outra pessoa ou alguma coisa. he is a theater lover / ele é apaixonado por teatro.

Levando-se em consideração o contexto do enredo, a palavra 'lovers' pode muito bem ter o significado de 'amantes', visto que, na história do conto, Rita trai o marido, Vilela, com Camilo. É possível que o vocábulo lover tenha sido utilizado, de fato, para reforçar a ideia de que eles, Rita e Camilo, não formavam um casal convencional. Goldberg, como vemos, optou, portanto, por fazer tal tradução, caracterizando Rita e Camilo como lovers nesse ponto do conto. Podemos, inclusive, dizer que essa retomada da condição de amantes de Camilo e Rita, nesse momento do texto de Goldberg, nos faz inferir que esse tradutor possa ter feito novamente uso do recurso de clarificação, visto que inclui em seu texto uma informação não dita no trecho original, no entanto, faz parte de seu contexto.

Ainda sobre os segmentos 14 e 15, vemos que enquanto Goldberg faz da literalidade uma marca de sua tradução, Garcia construiu uma tradução que, apesar optar, em alguns momentos, por fazer uso de outras escolhas lexicais, não se distancia da caracterização original da cena. À exemplo disso, no segmento 15, podemos verificar que Garcia traduz a colocação nominal 'casa do encontro' como 'Their meeting spot'; já Goldberg retextualiza a expressão atribuindo à mesma um adjetivo que pode ocasionar algumas inferências sobre seu ethos discursivo. O adjetivo utilizado é 'secret' ('secreto', em português), cuja aparição no discurso pode, a nosso ver, dar a ideia de que o tradutor quis deixar em evidência o fato de que, no enredo, Camilo e Rita se encontravam às escondidas.

Reatentamos para o fato de ser possível perceber em excertos de traduções, como as apresentadas aqui, a presença de indicativos de opinião, os quais, por vezes, o tradutor imprime em seu discurso. No entanto, compreendemos que isso não significa que, nesses casos, se trate de uma retextualização equivocada. Ao contrário, demonstra que há diversas formas de retextualizar um discurso, e que os fatores que levam essa retextualização a se apresentar de uma maneira ou de outra são diversos.

Voltando à análise do segmento 15, daremos enfoque ao trecho 'olhando de passagem'. Aqui temos mais um exemplo de diferentes pontos de vista por parte dos tradutores com relação ao que é dito no original de Machado: temos 'keeping his eye open', na tradução de Goldberg, e 'glancing fleetingly', na de Garcia. As expressões verbais escolhidas por cada um dos tradutores indicam que ambos tiveram distintas opiniões e interpretações do original, tornando seus ethos discusivos aparentes. E isso nos faz inferir que ambos tiveram intenções um tanto distintas em suas traduções. Garcia, que utiliza o verbo 'to glance' (dar um olhar rápido, lançar os olhos) acompanhado do advérbio 'fleetingly' (rapidamente, passageiramente, transitoriamente) faz mostrar que o olhar de Camilo para a casa da cartomante houvesse sido ligeiro, instantâneo e casual. Já Goldberg emprega uma locução verbal de maior intensidade e foco emocional, 'to keep one's eye open', (olhar atentamente), a denotar, como se vê, atenção, em postura inteiramente oposta ao do personagem na tradução de Garcia.

Já falamos aqui sobre determinados "modos de dizer" que julgamos indício de posicionamentos do enunciador. Concentremos nossa averiguação sobre esse aspecto verificando como foram representados alguns adjetivos do texto original nas duas traduções, via o segmento 18 (Figura 5 a seguir). 


\begin{tabular}{|c|c|c|c|}
\hline Segmento & Original & Garcia & Goldberg \\
\hline 18 & \begin{tabular}{lr}
\multicolumn{3}{l}{ o princípio de } & 1869 , \\
voltou Vilela da \\
província, onde casara \\
com uma dama \\
formosa \\
tonta;abandonou a \\
magistratura e veio \\
abrir banca de \\
advogado.Camilo \\
arranjou-lhe casa para \\
os lados de Botafogo, \\
e foi a bordo recebê- \\
lo.
\end{tabular} & $\begin{array}{l}\text { At the beginning of } \\
\text { 1869, Vilela returned } \\
\text { from the countryside, } \\
\text { where he had married } \\
\text { a beautiful and } \\
\text { brainless lady. He } \\
\text { gave up the } \\
\text { magistracy and set up } \\
\text { a legal practice } \\
\text { instead. Camilo found } \\
\text { a house near Botafogo } \\
\text { for him and promptly } \\
\text { paid him a visit. }\end{array}$ & $\begin{array}{l}\text { At the beginning of } \\
\text { the year } 1869 \text { Villela } \\
\text { returned from the } \\
\text { interior, where he had } \\
\text { married a silly beauty; } \\
\text { he abandoned the } \\
\text { magistracy and came } \\
\text { hither to open a } \\
\text { lawyer's office. } \\
\text { Camillo had secured a } \\
\text { house for him near } \\
\text { Botafogo and had } \\
\text { welcomed him home. }\end{array}$ \\
\hline \multicolumn{4}{|c|}{ Figura 5} \\
\hline
\end{tabular}

Por meio dessa ilustração, vemos que o que marca a diferença um tanto sutil, mas aparente, entre as abordagens escolhidas por Goldberg e Garcia é o modo como os adjetivos do texto original foram retextualizados. Vemos no segmento 18 que Machado descreve Rita como 'uma dama formosa e tonta'. Goldberg retextualiza essa mesma passagem caracterizando Rita como 'a silly beauty', e Garcia como 'a beautiful and brainless lady'. Podemos perceber que os adjetivos utilizados em cada uma das traduções apresentam significados, em português, um tanto distintos. Para o trecho 'formosa e tonta', Garcia atribui certa falta de inteligência de Rita, visto que para 'brainless', recorrendo novamente ao Michaelis Moderno Dicionário Inglês \& Português (on-line), o dicionário promove os seguintes equivalentes: $i$. sem cérebro; ii. desmiolado; iii. descuidado. Apesar disso, pode-se observar que o significado equivalente que mais se encaixa ao sentido de brainless inserido no contexto em questão é o de 'lacking of intelligence; stupid'.

Apresentada esta análise, retomamos o fato de crermos que os adjetivos são escolhas lexicais que carregam um indicativo da opinião do tradutor, pois acreditamos que a escolha por determinada forma de caracterizar algo (seja uma situação, um objeto, ou alguém) é um ato particular de cada enunciador, visto que podem existir interpretações e pontos de vista diversos a respeito desse algo. Além disso, essas múltiplas interpretações podem surgir também por meio do uso de uma palavra que na língua-fonte possui diversas conotações.

Traremos aqui adiante outras comparações entre trechos do texto original e dos textos traduzidos analisados. Veremos que alguns deles foram reconstruídos com um vocabulário que, por vezes, aponta uma abordagem um tanto diferente em relação ao texto original. Entretanto, observaremos, ainda, que, de fato, os tradutores, em alguns casos, fizeram escolhas distintas entre si quanto ao vocabulário, mas que mantém alguma relação (explícita ou não), cada um à sua maneira, com o contexto dos respectivos trechos correspondentes presentes no original.

Vimos, até o momento, que o princípio da livre escolha e o princípio idiomático se fizeram presentes nas duas traduções aqui analisadas. Para explicitar o 
que são esses dois princípios, Costa (2005) recorre às definições estabelecidas por Sinclair $(1991)^{8}$, que afirma que o princípio da livre escolha é um modo de ver o texto como resultado de diversas escolhas complexas; já o princípio idiomático, ainda segundo Sinclair, diz que o usuário da língua dispõe de um grande número de sintagmas semi-pré-construídos que constituem opções unitárias, mesmo que possam parecer analisáveis em partes. A respeito desses dois princípios, Costa alega que:

Para revelar os dois princípios operantes num dado trecho, parece necessário considerar o princípio da livre escolha como sendo formado por dois tipos de escolha: a) lexical; b) gramatical; e o princípio idiomático como sendo constituído de três conjuntos diferentes de escolhas mais amplas: a) expressões idiomáticas; b) colocações; c) seqüências lexico gramaticais fixas. (p. 47)

Ressaltamos que o uso desses princípios em cada uma das traduções deve ter sido feito por diferentes motivos. Veremos que o princípio da livre escolha e o princípio idiomático, presentes na teorização de Costa, utilizados em cada uma das traduções, se fazem presentes nos trechos que examinaremos a seguir, e que sugerem impressões dos tradutores a respeito do enredo do texto. Como exemplo disso, temos o segmento 28 da Figura 6.

\begin{tabular}{|c|c|c|c|}
\hline Segmento & Original & Garcia & Goldberg \\
\hline 28 & $\begin{array}{l}\text { Palavras vulgares; } \\
\text { mas há vulgaridades } \\
\text { sublimes, ou, pelo } \\
\text { menos, deleitosas. A } \\
\text { velha caleça de praça, } \\
\text { em que pela primeira } \\
\text { vez passeaste com a } \\
\text { mulher amada, } \\
\text { fechadinhos ambos, } \\
\text { vale o carro de } \\
\text { Apolo. Assim é o } \\
\text { homem, assim são as } \\
\text { coisas que o cercam. }\end{array}$ & $\begin{array}{l}\text { Platitudes; but certain } \\
\text { platitudes are } \\
\text { sublime,or at least } \\
\text { delicious. The old } \\
\text { street carriage in } \\
\text { which you rode, for } \\
\text { the first time, with the } \\
\text { woman you love, } \\
\text { both concealed from } \\
\text { view, is as good as } \\
\text { Apollo's chariot. } \\
\text { Such is man, such are } \\
\text { the things that } \\
\text { surround him. }\end{array}$ & $\begin{array}{l}\text { Commonplace words, } \\
\text { it is true; but there are } \\
\text { sublime } \\
\text { commonplaces,-or } \\
\text { at least, delightful } \\
\text { ones. The old chaise } \\
\text { in which for the first } \\
\text { time you rode with } \\
\text { your beloved, } \\
\text { snuggled together, is } \\
\text { as good as the chariot } \\
\text { of Apollo. Such is } \\
\text { man, and such are the } \\
\text { circumstances that } \\
\text { surround him. }\end{array}$ \\
\hline \multicolumn{4}{|c|}{ Figura 6} \\
\hline
\end{tabular}

Pensamos ser este mais um exemplo para fortalecer nossa tese de que a diferença de escolhas lexicais de dois tradutores que tem o mesmo texto como base tem, possivelmente, relação direta com uma provável "influência” que, por vez, um tradutor pode sofrer de suas próprias conclusões tiradas a partir da interpretação do original.

\footnotetext{
${ }^{8}$ A referência desta obra pode ser encontrada em Costa (2005).
} 
O quadro acima traz a expressão "fechadinhos ambos", que em português já carrega uma carga simbólica particular, e que ganhou interpretações distintas e um tanto singulares por cada um dos tradutores em exame.

Vemos que Garcia traduziu a referida frase talvez com base numa provável dificuldade de conseguir encontrar um equivalente para 'fechdinhos ambos'; interpretou essa passagem do original como se os personagens estivessem "escondidos" - 'concealed from view' 9-, visto que 'conceal', de acordo com o Longman Dicionário Escolar de língua portuguesa e inglesa, significa 'esconder, ocultar'.

A tradução feita por Goldberg também é curiosa por apresentar muitas diferenças com relação ao original, ainda que, ao lê-la, seja possível estabelecer certa relação com o texto de Machado em português. Para esse mesmo trecho, 'fechadinhos ambos', Goldberg fabrica a seguinte tradução: 'the first time you rode with your beloved, snuggled together'. Temos nessa tradução um detalhe que a distingue da de Garcia. Referimo-nos à ocorrência do adjetivo 'snuggled', cujo equivalente na língua portuguesa é algo próximo a 'aconchegado'.

Dada a explanação do significado dos termos que ocasionaram um enfoque diferente entre as traduções, eis a indagação que, pensamos, se torna apropriada fazer: e quanto ao fator 'opinião do tradutor', pelo qual vínhamos buscando em cada análise? Partimos aqui da tese de que ambos os tradutores foram levados pelas suas próprias impressões ao produzirem suas releituras do original. É provável que Goldberg tenha optado pelo vocábulo 'snuggle' na tentativa de escolher uma palavra cuja definição se aproximasse ao máximo a 'fechadinhos'; mas, ainda sim, ambas as traduções estabelecem certa semelhança com os dizeres - e claro, com o contexto - do texto em português.

Examinamos até o momento trechos que apresentaram interpretações distintas para determinadas passagens dos textos traduzidos, em virtude de algumas palavras utilizadas pelos tradutores possuírem significados bastante distintos, o que pode, por vezes, provocar interpretações diversas acerca do excerto de um texto. Vimos também que típicos exemplos como colocações e expressões idiomáticas podem ocasionar dificuldades no processo tradutório desses termos; mas, ainda sim, é possível, nesses casos, realizar uma tradução que cumpra, à sua maneira, o objetivo de se fazer entender e retextualizar o original de modo coerente.

Chegamos, pois, ao último segmento analisado em nosso estudo, que, inclusive, a nosso ver, é mais um exemplo a fortalecer nossa hipótese de que o tradutor insere indícios de opinião acerca do discurso que constroi.

\footnotetext{
${ }^{9}$ Como possivelmente se trata de uma linguagem figurada, não procuraremos atribuir teorias a respeito do significado dessa expressão, pois não faz parte do objetivo dessa pesquisa. Mas nos atentaremos, ao invés, na ampla diferença que há entre a forma como cada um dos tradutores optou por reproduzir sua tradução do trecho original.
} 


\begin{tabular}{|c|c|c|c|}
\hline Segmento & Original & Garcia & Goldberg \\
\hline 74 & $\begin{array}{l}\text { De volta com os } \\
\text { planos, reboavam-lhe } \\
\text { na alma as palavras } \\
\text { da cartomante. Em } \\
\text { verdade, ela } \\
\text { adivinhara o objeto } \\
\text { da consulta, o estado } \\
\text { dele, a existência de } \\
\text { um terceiro; por que } \\
\text { não adivinharia o } \\
\text { resto? }\end{array}$ & $\begin{array}{l}\text { Along with his plans, } \\
\text { the fortuneteller's } \\
\text { words echoed in his } \\
\text { soul. She had, in fact, } \\
\text { divined the purpose } \\
\text { of his visit, his state } \\
\text { of mind, the existence } \\
\text { of a third party: why } \\
\text { would it be hard for } \\
\text { her to divine the rest? }\end{array}$ & $\begin{array}{l}\text { Together with his } \\
\text { plans there kept } \\
\text { echoing in his soul } \\
\text { the words of the } \\
\text { fortune-teller. In } \\
\text { truth, she had guessed } \\
\text { the object of his visit, } \\
\text { his own state of mind, } \\
\text { and the existence of a } \\
\text { third; why, then, } \\
\text { wasn't it reasonable } \\
\text { to suppose that she } \\
\text { had guessed the rest } \\
\text { correctly, too? }\end{array}$ \\
\hline
\end{tabular}

Nesse segmento temos a seguinte frase: '(...) reboavam-lhe na alma as palavras da cartomante'. Pode-se se dizer que, ao analisarmos as opções lexicais nesse segmento, vemos que a discussão promovida na análise do segmento 8 da Figura 3 volta a esta pesquisa, pois aqui, na Figura 7 acima, temos o verbo 'reboar', que ambos os tradutores optaram por traduzir como 'echo', apesar de terem feito usos de tempos verbais diferentes. Notamos que essa escolha lexical tem um significado equivalente ao do verbo utilizado no texto original, como também pudemos observar que o contexto da história não foi perdido em nenhuma das traduções. No entanto, esse não é o único aspecto a ser analisado nas traduções feitas para esse trecho.

Com vistas a verificar outras possíveis opções de tradução para o verbo 'reboar', recorremos ao Michaelis Moderno Dicionário Inglês \& Português (on-line) e encontramos os seguintes equivalentes para este verbo na língua inglesa: 'reverberate', 're-echo', e 'resound'. Contudo, fazendo uma consulta no British National Corpus, é possível constatar que, dentre esses três termos, o primeiro, de acordo com a busca feita no referido corpus, é o que possui mais ocorrências, alcançando o número de 44 ocorrências. No entanto, há outro equivalente para o verbo reboar na lingua inglesa, bem como mostra o dicionário bilíngue de língua portuguesa e inglesa Longman Dicionário Escolar. Estamos falando do verbo echo, cuja ocorrência é, inclusive, ainda maior em comparação a todos os equivalentes supracitados. O verbo 'echo', novamente de acordo com o British National Corpus, possui 1.737 ocorrências. Destacamos aqui que ambos os tradutores optaram por uma escolha que privilegiou o aspecto semântico, através de um verbo em língua inglesa ‘echo' - de ampla corrência nessa língua. Julgamos válido ressaltar que, em nossa opinião, essas escolhas lexicais dos tradutores ('echoed' e 'kept echoing') mantiveram a carga de emoções demonstradas no texto original, com relação aos sentimentos do personagem Camilo. Nesse momento, é importante relembrar que, ao longo deste estudo, vimos analisando cada segmento do ponto de vista não só dos conceitos tradutológicos que escolhemos para fundamentar esse estudo, mas vimos também 
promovendo um exame da abordagem escolhida por cada tradutor com o intuito de verificar em que circunstâncias (partindo-se da hipótese de que essas circunstâncias existem) uma tradução pode indicar pistas de que seu respectivo enunciador-tradutor não está somente traduzindo o texto original, mas, igualmente, adicionando suas próprias impressões a respeito do que aquele texto diz, por meio de determinados modos de se expressar.

Ao falarmos nesse aspecto, relembramos que estamos nos referindo ao conceito de ethos discursivo de Maingueneau, que afirma dele: está crucialmente ligado ao ato de enunciação (2006, p. 268). Façamos uma retomada do posicionamento desse autor. Segundo ele o ethos discursivo reúne aquelas características que indicam algo sobre a personalidade do enunciador, mas não por meio do que ele fala de si, mas sim, explicitamente, pelo modo como ele se expressa e se importa com relação ao que está falando.

Voltando ao objeto da análise presente, pensamos ser relevante mencionar que apesar de ambos os tradutores terem optado por utilizar o mesmo verbo para traduzir a palavra 'reboar', vemos que uma certa escolha gramatical marca uma diferença de ênfase aspectual na reconstrução da cena. Vemos que Goldberg, para o trecho correspondente no texto original - 'De volta com os planos, reboavam-lhe na alma as palavras da cartomante.' -, fez a seguinte tradução: 'Together with his plans there kept echoing in his soul the words of the fortune-teller'. Já Garcia construiu a seguinte retextualização: 'Along with his plans, the fortuneteller's words echoed in his soul'.

Podemos perceber a diferença entre as escolhas de ordem gramatical de cada tradutor ao fazerem uso de tempos verbais distintos para apresentar a ideia do texto original. Atentos às retraduções dos tempos verbais nas duas frases, percebemos que o Google translator, por exemplo, fornece um mesmo equivalente para 'kept echoing' e 'echoed': 'ecoavam'. No entanto, pensamos ser relevante atentar para a diferença entre essas estruturas verbais em cada uma das frases. A respeito da escolha gramatical feita por Goldberg, 'there kept echoing', sabemos que o sufixo '-ing' na língua inglesa faz referência a ações contínuas. Sendo assim, podemos interpretar que essa frase quereria dizer em português o seguinte: '(...) as palavras da cartomante ficaram ecoando (...)'. Dito isso, se formos vincular ao nosso raciocínio o conceito de ethos discursivo extraído da Análise do Discurso, parece provável que essa escolha gramatical feita por Goldberg não tenha sido feita meramente ao acaso. $\mathrm{O}$ fato de Goldberg ter optado por uma estrutura verbal que explicita a ação como duradoura, nos sugere que o tradutor pode ter tido a intenção de explicitar que as palavras da cartomante ficaram na mente do personagem Camilo ou que surgiram em sua mente por repetidas vezes. Entende-se, portanto, que essa sutil diferença de escolha entre os tradutores nos indica que um deles optou por enfatizar, ou explicitar, seu posicionamento com relação ao enredo.

Considerações finais

Chegamos à conclusão deste artigo, após cada segmento escolhido para comentários foi exposto à análise de forma a buscar identificar as semelhanças e diferenças entre as abordagens adotadas por cada enunciador-tradutor. Em resumo, buscamos investigar como um enunciador-tradutor que constroi um texto com base em outro se apropria do texto original que toma por base. Procuramos conduzir a busca por respostas a essa indagação a partir de conceitos das duas vertentes acadêmicas citadas: o conceito de ethos discursivo, da Análise do Discurso, e os conceitos de equivalência, clarificação e retextualização, dos Estudos da Tradução. 
Costa (2005) afirma sobre a tradução que "o texto original limita o novo texto de inúmeras maneiras, sendo a mais visível delas o fato de que o texto do tradutor deve ter um alto grau de semelhança com o seu correspondente original para que seja reconhecido como uma tradução". (p. 26). Ainda que concordemos com essa afirmação, foi possível perceber que nas traduções analisadas, esse limite lembrado por Costa não se tornou empecilho para que os tradutores conseguissem produzir suas releituras do texto original. Mais que isso, mesmo nos trechos em que os tradutores fizeram da literalidade uma marca de sua tradução - como na tradução de ' $a$ senhora gosta de uma pessoa', traduzido por Goldberg como 'the lady likes a certain person' - foi possível perceber que as escolhas lexicais de cada tradutor podem possivelmente ter sido agregadas à tradução com algum propósito especifico.

Vimos ainda, que em determinados trechos de ambas as traduções, os tradutores não fizeram uso de literalidade - como em 'you are in love with someone', tradução feita por Garcia para a frase 'a senhora gosta de uma pessoa', presente no original, e em 'but that there were no grounds for me to fear', forma pela qual Goldberg optou traduzir o original - 'mas que não era verdade' - apresentando do mesmo modo traduções adequadas em relação ao contexto do original.

Também foi possível observar que, por vezes, os tradutores fizeram uso de determinados recursos de linguagem que, de certa forma, auxiliam a revelar na tradução algum aspecto do original, promovendo um olhar sob outro ponto de vista a respeito do enredo.

Procuramos atribuir àquilo que Berman chama de tendências deformadoras uma visão positiva, pois entendemos que todo e qualquer recurso utilizado para construir uma tradução é válido desde que não resulte em um discurso que não represente o contexto de forma inapropriada e que esteja de acordo com o que é dito no texto original, guardando o "grau de semelhança” mencionado acima que permite reconhecer uma tradução como tal.

Ao analisarmos determinadas passagens das traduções, vimos que algumas delas diferiram entre si, mas que apresentaram também uma mensagem relacionável ao enredo original e a diversas de suas nuances. E justamente pelo fato de termos identificado momentos em que as traduções não se apresentaram iguais, acreditamos na hipótese de que o modo de se expressar de cada enunciador-tradutor teve a influência de suas próprias impressões a respeito do contexto do conto. Portanto, quanto ao fator “opinião”, pensamos que não só é aceitável que um tradutor as tenha como cremos que sua ocorrência é praticamente inevitável em um texto traduzido, o que esperamos ter mostrado através dos trechos analisados. Entendemos que toda e qualquer escolha de um tradutor está vinculada a um propósito que esse tradutor tem. O fato de adotar uma abordagem demonstra, a nosso ver, que este tradutor não está distante do texto que escreveu. Além disso, do fato que o texto traduzido deva apresentar relação com o original, não significa que, em princípio, a ocorrência - por vezes aparente - da interpretação do tradutor torne sua tradução inadequada; como vimos, a manutenção do contexto original é plenamente realizável.

Entretanto, assim como toda regra possui sua exceção, pensamos ser importante ressaltar que cada interpretação que fizemos e apresentamos para cada caso é uma entre tantas interpretações possíveis. Assim como a Análise do Discurso afirma que cada discurso é particular de cada enunciador, podemos dizer que cada leitor, ao se deparar com duas ou mais versões traduzidas de um mesmo discurso tais quais as deste estudo -, poderá fazer suas próprias inferências e ter interpretações 
diferentes sobre o que determinado enunciador-tradutor pretendeu ao traduzir de uma determinada maneira.

Vanessa Silva Fischer

vanessa.fsch@gmail.com

Licenciada em Letras, PUC/RS

Heloísa Orsi Koch Delgado

heloisa.delgado@pucrs.br

Pontifícia Universidade Católica do Rio Grande do Sul

\section{Referências}

ASSIS, Machado de. Contos: uma antologia. 2. ed. São Paulo: Companhia das Letras, 2004.

BERMAN, Antoine. A tradução e a letra ou o albergue do longínquo. Rio de Janeiro : 7 Letras, c2007. 143 p.

COSTA, W. O Texto Traduzido como Re-textualização. Cadernos de Tradução. Vol. 2, no. 16. Santa Catarina: UFSC, 2005.

DO BRASIL, LONGMAN. Longman dicionário escolar Português-Inglês/InglêsPortuguês. Ed. Longman do Brasil, 2008. 774p.

GARCIA, R. A. N. (Org.); ALEXANDER, I. (Org.). A Machado de Assis Anthology (New Translations of Brazilian Classics). Amazon Kindle Edition, 2011.

GOLDBERG, Isaac. (Org.). Brazilian tales. Boston: International Pocket Library, 1921.

GOOGLE TRANSLATOR. Disponível em: http://translate.google.com.br/ Discurso literário. São Paulo: Contexto, 2006. 329 p. Análise de textos de comunicação. 2. ed. São Paulo : Cortez, 2002. $238 \mathrm{p}$.

Melhoramentos. Michaelis Moderno Dicionário Inglês \& Português. Editora Melhoramentos Ltda. - nova ortografia. Disponível em <http://michaelis .uol.com.br/moderno/ingles/index.php>

University of Oxford. The British National Corpus (BNC), 2007. Disponível em $<$ http://www.natcorp.ox.ac.uk/> 